\title{
Unveiling a multilayered regulatory network of NONEXPRESSOR OF PATHOGENESIS-RELATED GENES1 - A central node of salicylic acid-mediated plant defense
}

\author{
Jian Chen ${ }^{1}$, Jingyi Zhang ${ }^{2}$, Mengmeng Kong ${ }^{3}$, Andrew Freeman ${ }^{4}$, Huan Chen ${ }^{2}$, and \\ Fengquan $\mathrm{Liu}^{2}$ \\ ${ }^{1}$ Jiangsu University \\ ${ }^{2}$ Jiangsu Academy of Agricultural Sciences \\ ${ }^{3}$ Nanjing Agricultural University \\ ${ }^{4}$ University of South Carolina
}

September 23, 2020

\begin{abstract}
Salicylic acid (SA) plays pivotal roles in plant defense against biotrophic and hemibiotrophic pathogens. Tremendous progress has been made in the field of the SA biosynthesis pathways and SA-mediated plant defense signaling networks in the past three decades. As one of the SA receptors, NONEXPRESSOR OF PATHOGENESIS-RELATED GENES1 (NPR1) functions as a master regulator of SA-mediated plant defense. The function of NPR1 is tightly regulated by transcriptional and posttranslational regulation. This review discusses recent advances in SA and NPR1 biology, including SA perception, SA signaling, the function of SA and NPR1 in plant immunity, and the transcriptional and post-translational regulation of NPR1.
\end{abstract}

\section{Hosted file}

NPR1 review PCE.pdf available at https://authorea.com/users/361389/articles/482787-unveilinga-multilayered-regulatory-network-of-nonexpressor-of-pathogenesis-related-genes1-acentral-node-of-salicylic-acid-mediated-plant-defense 

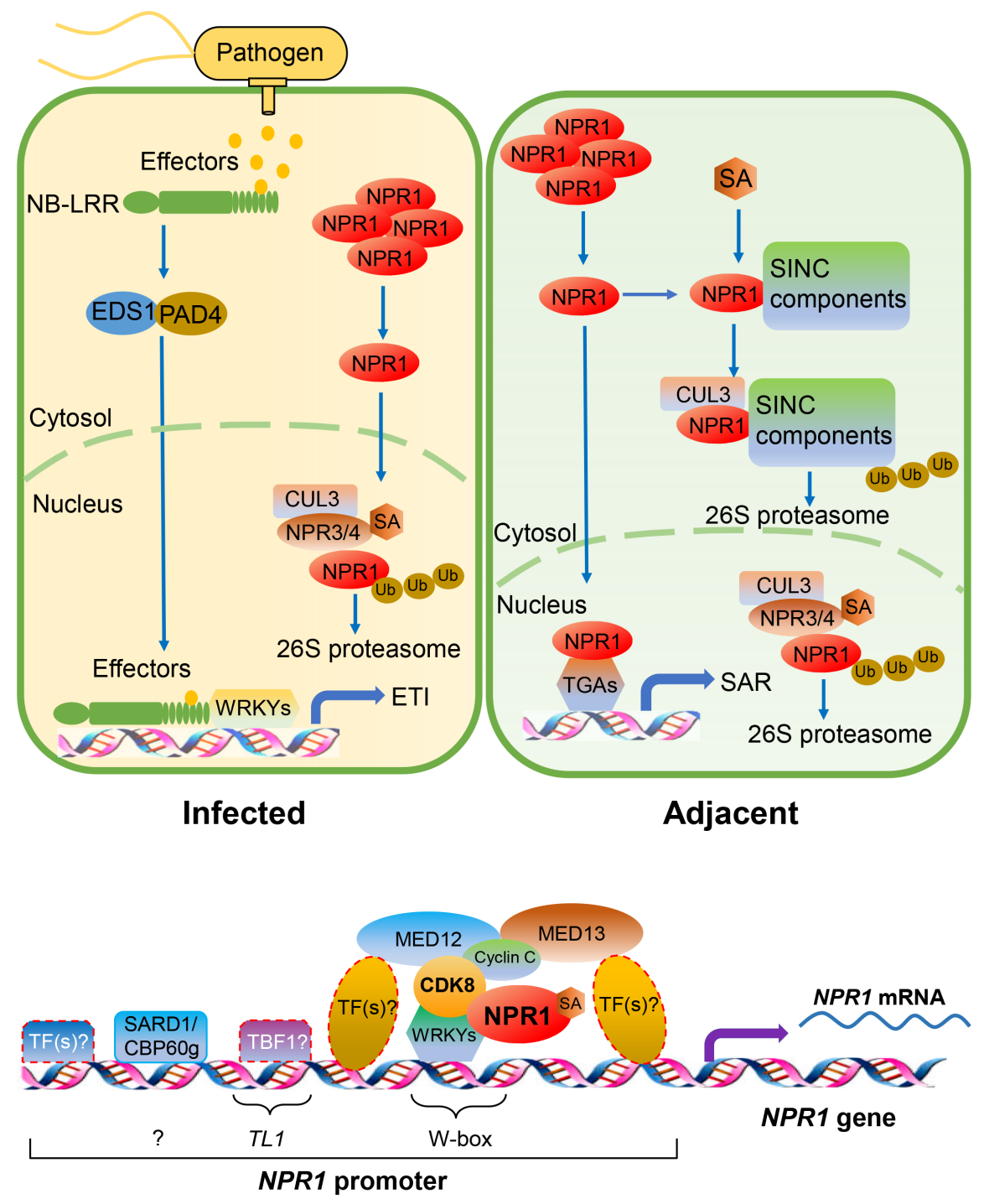


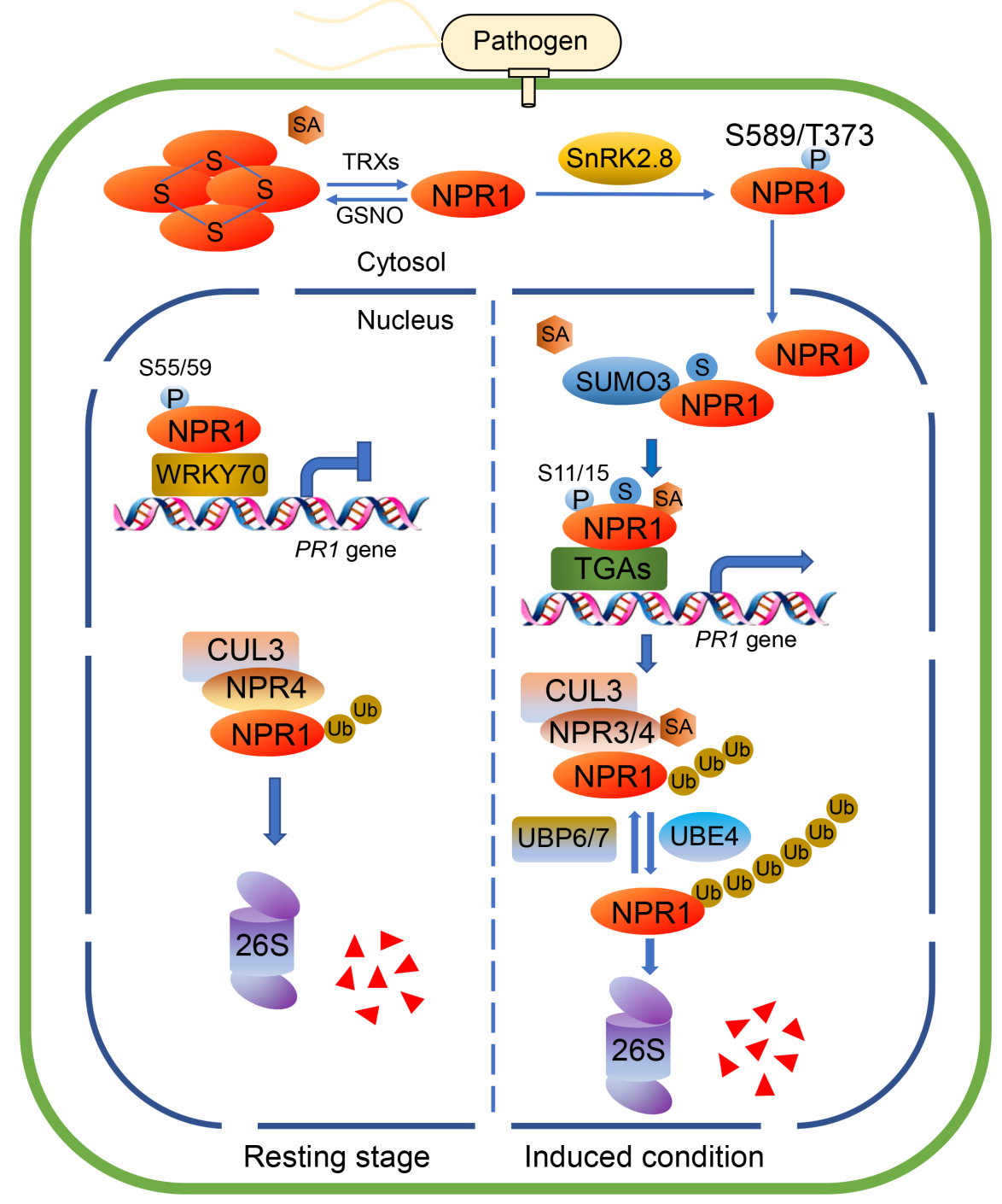

